\title{
Incidence and risk factors of oroantral perforation following tooth ex- traction among Nigerian population in a tertiary hospital: a ten-year retrospective study
}

\begin{abstract}
Ekaniyere Benlance
EDETANLEN. FWACS (Oral \& Maxillofacial surgery) - Lecturer 1, Department of Oral and Maxillofacial surgery, School of Dentistry College of Medical Sciences, University of Benin, Benin-city, Edo state, Nigeria. Email: ehiben2002@yahoo.com
\end{abstract}

\section{Birch Dauda SAHEEB}

FWACS, FDSRCS (Edin) - Professor, Department of Oral and Maxillofacial surgery, School of Dentistry College of Medical Sciences, University of Benin, Benin-city, Edo state, Nigeria. Email: dauda2000@yahoo.com

\begin{abstract}
Oro-antral perforation (OAP) could be misdiagnosed if the incidence and risk factors are unknown and its consequence could be worrisome. We aimed to determine the incidence and risk factors of oro-antral perforations after teeth extraction. A retrospective study of forceps extracted upper posterior teeth over a ten-year period from September 2008 to November 2018 was done at our hospital in Nigeria. In univariate analysis, the predictors were age, gender, experience of surgeon, site of tooth, side of surgery, use of elevators while the outcome variable was oroantral perforations. Logistic regression was also done to determine the risk factors associated OAP. We used SPSS Version 17(SPSS Inc, Chicago, USA) to perform descriptive and inferential statistical analysis. P-Value less than 0.05 was considered statistically significant. Out of the total 26,372 dental extractions during the ten-year period, 54 (0.2\%) extraction cases (33 males, 21 females) had oro-antral perforations. Their mean age was 54.8 $\pm 10.6 y e a r s$ (ranging from 21 to78 years). The highest incidence occurred in the sixth decade of life. Only the location of teeth had a significant association with oro-antral perforations. The location of upper first molar was $(\mathrm{OR}=1.85, \mathrm{P}=0.00)$ identified as a significant risk factor. The incidence of OAP is significantly lower in Nigerians and was $0.2 \%$ although there could be a population variability. The position of the upper first molar was a factor found to be associated and predictive of the OAP but age, gender, number of extractions per visit, side of operation and the surgeon's experience were not. The findings will help surgeons to predict occurrence of OAP knowing its risk factors.
\end{abstract}

KEYWORDS: incidence, oro-antral perforation, risk factors, simple tooth extraction

\section{INTRODUCTION}

Tooth extraction remains the most performed procedure in the outpatient clinic of general dental practitioners and oral surgeons worldwide ${ }^{(1)}$. Though it is described as a simple procedure, complications can result following extraction of upper posterior teeth even in the hands of an experienced surgeon, thereby causing patient's discomfort and poor quality of life ${ }^{(2)}$.

Oro-antral perforation (OAP) as one of the complications of tooth extraction, is an unnatural communication between the oral cavity and the maxillary sinus ${ }^{(3)}$. The maxillary sinus forms a large part of the maxilla, normally extending into the alveolar process adjacent to the apices of the posterior teeth. The various terminologies that have been used to described the condition ranged from oro-antral communication $(\mathrm{OAC})^{(4)}$ oro-antral fistula (OAF) (5) to antro-alveolar fistula $(\mathrm{AAF})^{(6)}$, or oro-sinusal communication (OSC) ${ }^{(7)}$, but it appears that OAF and

$\mathrm{OAC}$ are the most commonly used terminologies in a synonymous fashion by most clinicians. However, consensus has been reached that OAF should be used for an epitheliarised communication path between the maxillary sinus and the oral cavity ${ }^{(2,4)}$.

The risk factors to the occurrence of (OAP) are age, gender, cortical bone thickness, sinus floor, thickness of sinus membrane, anatomical variation, surgeon's experience, and tooth location ${ }^{(8,9)}$. Other risk factors include isolated teeth, root fusion, root divergence, root hypercementosis, periapical cyst and tumors $^{(10,11)}$. Sinusitis, antral-polyp, antral-herniation following an untreated OAP can be avoided in the absence of misdiagnosis. However, most OAP may be undiagnosed at the time of occurrence if these risk factors are not known ${ }^{(12)}$.

Its occurrence is rare in children during extraction due to the presence of permanent teeth buds and the underdeveloped maxillary sinus ${ }^{(13)}$.

The incidence of OAP as a result of extraction of all posterior maxillary teeth varies from $0.31 \%$ to 3.8 $\%^{(1-14)}$. Complex extraction of maxillary third molars were reported to cause incidence of $4.9 \%$ to $5 \%{ }^{(15)}$. In another experiment overall incidence of both simple and complex tooth extraction of upper third molars were reported as $5.1 \%{ }^{(16)}$. Previous studies reported the second premolars as the highest risk of creating OAC during extraction, unlike recent studies that reported the molar teeth that have their roots in closest proximity to the sinus floor ${ }^{(17,18)}$. Study by Killey and Kay (1967) reported that $50 \%$ of the cases occurred after the removal of the first molar on their analyses of 250 cases 1 . As reported by Hirata et al., ${ }^{(15)}$ the perforation rate occurred most often after the extraction of the upper first molar, and that it 
was significantly higher in males who were in their third decade of life. Punwutikorn et al (12) reported that the older the patient, the higher the chances of having OAF after simple extraction. The authors have also shown that the extraction of the first molar is commonly associated with OAF. However, Guven ${ }^{(17)}$ opined that second molar extraction followed by the first molar had the highest risk

The incidence of OAP following simple and or complex tooth extraction of all upper posterior teeth or maxillary third molars are well reported in the Asians and Caucasians $1{ }^{(13-15)}$ but the incidence of OAP following simple extraction of upper posterior teeth among the Africans seem unclear. The risk factors involved in OAP development during complex removal of upper third molar have been previously reported $^{(5,14)}$ nevertheless, this remains to be defined following simple extraction of all upper posterior teeth. Thus, the present study, attempts to determine the incidence of OAP following extraction of all upper posterior teeth among Nigerians, and defined the risk factors associated with the appearance OAP.

\section{PATIENTS AND METHODS}

Due to the retrospective nature of this study, it was granted written exemption by the Research and Ethics Committee of the hospital. Data were obtained from the case notes of all patients that underwent extraction of upper posterior teeth between September 2008 and November 2018. Patients below 18 years and who had incomplete information in case notes were excluded from the study. Collected data were age, gender, experience of the surgeon, tooth location, side of surgery, use of elevators, time of diagnosis, and presence of oro-antral perforation.

OAP was diagnosed when patients complained of unilateral epistaxis or fluid regurgitation during and/or after dental extractions. The condition was confirmed by inspection and blunt probe test. The perforation was further identified as oro- antral communication (OAC) and oro-antral fistula (OAF) based on the time of occurrence to the time of diagnosis. OAP of less or equal to one week was considered $\mathrm{OAC}$ while that greater than one week was $\mathrm{OAF}^{(22)}$.

Surgical correction procedures were performed under local anaesthesia using 2\% lidocaine with adrenalin 1:100,000. After the procedure, 500mg amoxicillin, $200 \mathrm{mg}$ metronidazole, $1000 \mathrm{mg}$ paracetamol, and warm saline mouth rinse, all the patients had these prescriptions three times daily for 7 days. OAPs with diameter greater than $5 \mathrm{~mm}$ were closed surgically despite the duration of occurrence.
Acute sinus disease was treated with amoxicillin/ clavulanate $1 \mathrm{~g} / 125 \mathrm{mg} \times 3 \mathrm{~d}$ for $10-14$ days, nasal decongestants and NSAIDs. Chronic sinus disease underwent Caldwell Luc procedure.

In the descriptive analysis, continuous data were summarised as ranges, means and standard deviations while that of categorical data were summarised as frequency counts and percentages. In univariate analysis, the predictors were age, gender, experience of operator, tooth location, side of surgery, use of elevators while the outcome variable was oroantral perforations. Where univariate statistics were significant, multivariate analysis was performed. Logistic regression was also done to determine the risk factors associated OAP. We used SPSS Version 17(SPSS Inc, Chicago, USA) to perform descriptive and inferential statistical analysis. All tests were 2-sided and P-Value less than 0.05 was considered statistically significant.

\section{RESULTS}

The records of 26,372 patients that underwent extraction of upper teeth were studied. Among them; 11,192 were male and 15,180 were female; with mean (SD) age of 64.7(14. 2) years ranging from 19-105 years. Out of the total of 26,372 dental extractions during the ten-year period, $54(0.2 \%)$ extraction cases (33 male, 21 female) had oro-antral perforations. Their mean age was $54.8 \pm 10.6 y$ ears (ranging from 21 to 78 years). The highest incidence occurred in the sixth decade of life. The time of diagnosis of oro-antral perforation is presented in Table 1. Most (48.2\%) cases of oro-antral perforations were diagnosed at the time of tooth extraction while others were diagnosed postoperatively.

Table 2 shows univariate analysis of risk factors associated with oroantral perforation following extraction of posterior maxillary teeth. The patient's age, gender, surgeon's experience, use of elevators, and operation side did not statistically affect the occurrence of oro-antral perforation. The rate of oroantral perforation rate was associated with the type of teeth extracted and this relationship was statistically significant $(\mathrm{P}=0.03)$. Table 3 shows multivariate analysis of risk factors associated with oro-antral perforation following extraction of posterior maxillary teeth. In the binary logistic regression, oroantral perforation was considered as primary outcome variables with age of patients, gender, surgeon's experience, side of operation, use of elevators, and type of teeth extracted as the predictors (table 3). Only the type of teeth of first molars $(\mathrm{OR}=1.85, \mathrm{P}=0.00)$ 
was identified as a significant risk factor. Patients with acute uninfected perforations less than $5 \mathrm{~mm}$ were monitored for spontaneous healing while those with perforations larger than $5 \mathrm{~mm}$ were treated surgically. Patients with mild or moderate OAF were treated with local flap procedures such as palatal or buccal flap while those with larger OAF had distant flap. No root or tooth displacement into the maxillary sinus was recorded. All patients had amoxicillin/clavulanate $1 \mathrm{gm} / 125 \mathrm{mgx} 3 \mathrm{~d}$ for 10-14 days, nasal decongestant, and NSAIDs. Failure of flap was identified in one patient with buccal advancement flap and this was retreated with palatal rotation flap with successful outcome.

\section{DISCUSSION}

Forcep extraction of teeth is a procedure that is safe and predictable with low morbidity ${ }^{(23)}$. However, it is not free of complications, which may lead to increased treatment time and cost, additional surgery and medico-legal cases. Risk factors that can predict these complications ought to be recognised by clinicians

The present study showed $0.20 \%$ overall incidence of OAP. The incidence of OAPs reported in the literature varies, according to the type of studies and the samples. Furthermore, to a greater extent the incidence of OAPs previously reported varied, likely because some authors reported on the number of OAPs associated with the whole lateral segments, unlike others that reported solely on the incidence of OAPs after maxillary third molar removal. Rothamel et al5found incidence of OACs of $13 \%$ after removal of the maxillary third molars. Bonder et all6found an incidence of $5 \%$ after removal of premolars and molars in the maxilla. The incidence of OAPs as a result of tooth extraction of maxillary posterior, "antral", teeth varies from $0.31 \%$ to $3.8 \%$ as reported in the literature ${ }^{(13-16)}$ (Table 4$)$. The $0.20 \%$ incidence of OAPs after extraction of upper posterior teeth in the present study further increases the wide variability of incidence of OAPs after tooth extraction globally. The present study reported the lowest incidence of OAPs which differ greatly from previous studies ${ }^{(2,5,7)}$.The probable reason could be the anatomical variation in the craniofacial complex among the different population $^{(22)}$. The cortical lamellar bone separating the apices of maxillary teeth is reported to be thicker in the black population compared to the Asians and the Caucasians. ${ }^{(22)}$ The cortical thickness of the sinus floor is the bone between the maxillary sinus and the apices of the maxillary teeth ${ }^{(22)}$.

The average age of occurrence of OAP in this study was 54.8 years and the highest incidence of OAP was seen in the sixth decade of life. Similar findings by Punwutikorn et $\mathrm{al}^{(2)}$ were higher incidence of OAP in the elderly ${ }^{(2)}$. Increase incidence of OAP tends towards ages greater than 55 years (table 2), though age seems not to be significant risk factor $(\mathrm{P}=0.21)$ in its development. Increase pneumatisation with age could be the possible explanation ${ }^{(22)}$. Additionally, simple extraction is relatively difficult in the elderly due to some degree of bone sclerosis in this group of population ${ }^{(22)}$. These findings are in contrast to that of Rothamel et al5, and Światkowski et al., ${ }^{(13)}$ who reported higher incidence in individuals less than 30 years. Variations in this report could be the sample size studied or due to the type of tooth removal procedure performed.

More males tend to developed OAP as compared to females, although gender had no significant statistical association. This finding was corroborated in previous studies ${ }^{(6,8,13)}$ but was in contrast to the report of Światkowski et $\mathrm{al}^{(13)}$ who found higher incidence of $\mathrm{OAC}$ in females.

Although the side of the mouth operated on was not associated with statistically significant risk factor, an increase in OAP was noted on the left side of the mouth more than the right side. This finding supports previous study reported by Światkowski et $\mathrm{al}^{(13)}$. It could be that extraction on the left side of the maxilla seems more difficult probably due to the right-hand dominance of the operator ${ }^{(13)}$.

The highest incidence of OAP was seen in cases treated by the students and least in the patients treated by consultants, however this was not statistically significant. Most extractions are performed by students, which could probably account for the increase incidence in OAP in the cases treated by the students. This finding lends credence to the finding of Rothamel et $\mathrm{al}^{(5)}$ who reported that no association exists between operator's experience and the incidence of OAP.

Although the use of dental elevators during tooth extraction was not associated with a statistically significant risk of OAP, an increase in perforation rate was noted for extractions without elevation. Therefore, the probable reason for higher incidence of OAP without the use of elevator could be that most cases were performed by students who are not permitted to use elevators during extraction. The judicious use of elevators can help reduce the force of forcep application which makes extraction less difficult $^{(25)}$.

Numerous studies including case studies ${ }^{(1-7)}$ have 
implicated maxillary first molar as the commonest cause of OAPs. However, few studies have reported contrary findings. According to Marszi ${ }^{(23)}$, the connection and closeness between the socket and maxillary sinus are most common in second molars. Studies conducted by Franco-Carro et $\mathrm{al}^{(24)}$ revealed the extraction of third molars as the primary cause of OAC, followed by first molars, second molars, the second and first premolars and finally canines. The location of the teeth in the maxilla was the only significant risk factor that predicted OAP in the patients and this risk is highest with the maxillary first molar. Though several previous studies ${ }^{(2,5,8-14)}$ have also implicated first molars, but no study seems to have reported an association between location of tooth and incidence of OAP. The variability observed could be due to the closeness of the antral teeth and the orientation of the palatal roots of the first molars ${ }^{(23)}$ to the antral floor

Epithelisation of the communication is a strong prognostic factor in treatment outcome and most previous studies ${ }^{(13-15)}$ on incidence of perforation undermined this in their reports. The incidence of epithelised perforations (OAF) was lower as compared to the acute communication (OAC) (table 1).

The main limitation of this study was lack of radiographic records. In conclusion, the incidence of OAP is significantly lower in Nigerians and was $0.2 \%$ although there could be a population variability.
The position of the upper first molar was a factor found to be associated and predictive of the OAP but age, gender, number of extractions per visit, side of operation and the surgeon's experience were not.

\section{COMPLIANCE WITH ETHICAL STANDARDS}

Conflict of Interest: Dr Ekaniyere Benlance EDETANLEN declares that he has no conflict of interest. Professor Birch Dauda SAHEEB declares that he has no conflict of interest.

Funding: There was no funding for this work

Ethical approval: This article does not contain any studies with human participants or animals performed by any of the authors. Due to the retrospective nature of this study, it was granted written exemption by the Research and Ethics Committee of the hospital.

Informed consent: For this type of study, formal consent is not required.

\section{FIGURE LEGENDS}

- Table 1.Incidence oroantral perforation by time of diagnosis

- Table 2. Univariate analysis of risk factors associated with oroantral perforation following simple extraction of posterior maxillary teeth $(\mathrm{n}=54)$.

- Table 3. Multivariate analysis of risk factors associated with oroantral perforation following simple extraction of posterior maxillary teeth

- Table 4. Global incidence of oroantral perforations following tooth extraction

Table 1.Incidence oroantral perforation by time of diagnosis

\begin{tabular}{|c|c|}
\hline Time of diagnosis & Frequency (\%) \\
\hline Time of occurrence & $26(48.2)$ \\
\hline From time of occurrence to 7 days & $10(18.5)$ \\
\hline After 7 days post-occurrence & $18(33.3)$ \\
\hline Total & $54(100)$ \\
\hline
\end{tabular}

Table 2. Univariate analysis of risk factors associated with oroantral perforation following simple extraction of posterior maxillary teeth $(n=54)$.

\begin{tabular}{|c|c|c|}
\hline Variables & Number (\%) & P-Value \\
\hline \multicolumn{3}{|l|}{ Age(Years) } \\
\hline$\leq \mathbf{5 5}$ & $17(31.5)$ & 0.21 \\
\hline$>55$ & $37(68.5)$ & \\
\hline \multicolumn{3}{|l|}{ Gender } \\
\hline Male & $31(57.4)$ & 0.62 \\
\hline Female & $23(42.6)$ & \\
\hline
\end{tabular}




\begin{tabular}{|l|c|c|}
\hline \multicolumn{1}{|c|}{ Variables } & Number (\%) & P-Value \\
\hline \begin{tabular}{|l|} 
Operator Experience \\
Students
\end{tabular} & $18(33.3)$ & 0.43 \\
\hline Junior Residents & $13(24.1)$ & \\
\hline $\begin{array}{l}\text { Senior Residents } \\
\text { Consultants }\end{array}$ & $15(27.8)$ & \\
\hline Use of elevator & $08(14.8)$ & \\
\hline Yes & $21(38.9)$ & 0.08 \\
\hline No & $33(61.1)$ & \\
\hline Operation Side & \\
\hline Right & $22(40.7)$ & 0.42 \\
\hline Left & $32(59.3)$ & \\
\hline Type of teeth & \\
\hline Canine & $1(1.85)$ & 0.03 \\
\hline First Premolar & $9(16.7)$ \\
\hline Second Premolar & $7(13.0)$ \\
\hline First Molar & $18(33.3)$ \\
\hline Second Molar & $15(27.8)$ \\
\hline Third Molar & $4(7.41)$ & \\
\hline
\end{tabular}

Table 3. Multivariate analysis of risk factors associated with oroantral perforation following simple extraction of posterior maxillary teeth

\begin{tabular}{|c|c|c|c|}
\hline Risk factors & SE & OR(95\% CI) & P-Value \\
\hline Age $\leq 45$ years & 0.53 & $0.37(0.19-1.59)$ & 0.42 \\
\hline Female gender & 0.61 & $0.94(0.51-3.28)$ & 0.79 \\
\hline Students & 0.29 & $0.21(0.09-0.74)$ & 0.63 \\
\hline Junior residents & 0.63 & $0.83(0.42-1.21)$ & 0.21 \\
\hline Senior residents & 0.24 & $0.71(0.13-2.50)$ & 0.48 \\
\hline Consultants & 0.81 & $0.29(0.06-0.59)$ & 0.53 \\
\hline Use of elevator & 0.37 & $0.15(0.07-1.75)$ & 0.07 \\
\hline Left side of operation & 0.64 & $0.32(0.19-2.60)$ & 0.85 \\
\hline Canine & 0.16 & $0.19(0.04-1.09)$ & 0.37 \\
\hline First premolar & 0.38 & $0.62(0.41-0.97)$ & 0.21 \\
\hline Second premolar & 0.41 & $0.81(0.05-2.43)$ & 0.73 \\
\hline First molar & 1.85 & $3.84(1.76-8.90)$ & 0.00 \\
\hline Second molar & 0.92 & $0.71(0.31-0.94)$ & 0.35 \\
\hline Third molar & 0.48 & $0.34(0.08-2.57)$ & 0.49 \\
\hline
\end{tabular}


Table 4. Global incidence of oroantral perforations following tooth extraction

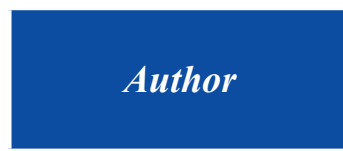

Beckedorf et $\mathrm{al}^{(21)}$
Punwutikorn et $\mathrm{al}^{(2)}$
Hirata et al1 $1^{(5)}$
Arrigoni et al ${ }^{(14)}$
del Rey Santa ${ }^{(7)}$
Rothamel et al ${ }^{(5)}$
Swiatkowski et al ${ }^{(13)}$
Present study
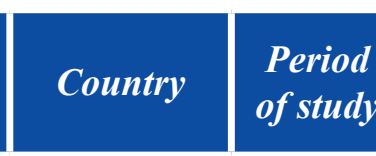

Germany
Thailand

1954

Japan

\begin{tabular}{l} 
France \\
\hline Spain \\
\hline
\end{tabular}

Germany

Poland

Nigeria

2001

2004

2014

2018
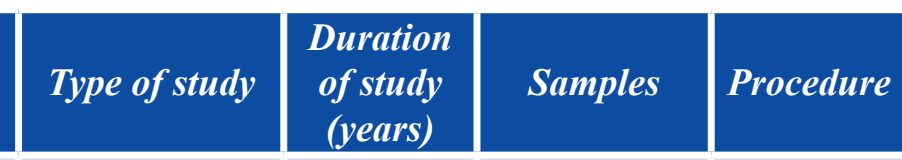

$*$

1994 Retrospective

2006

2007

Retrospective

Retrospective

Prospective

\begin{tabular}{|l|}
\hline Prospective \\
Prospective \\
\hline Prospective \\
Retrospective \\
\hline
\end{tabular}

$*$
9

$*$
APT

$*$

\begin{tabular}{|c|c|}
\hline $\begin{array}{c}\text { Simple } \\
\text { extraction }\end{array}$ & 0.31 \\
\hline $\begin{array}{c}\text { Simple } \\
\text { extraction }\end{array}$ & 3.80 \\
\hline $\begin{array}{c}\text { Complex } \\
\text { extraction }\end{array}$ & 4.90 \\
\hline $\begin{array}{c}\text { Simple }+ \\
\text { Complex } \\
\text { extraction }\end{array}$ & 5.10 \\
\hline $\begin{array}{c}\text { Complex } \\
\text { extraction }\end{array}$ & 5.00 \\
\hline $\begin{array}{c}\text { Simple } \\
\text { extraction }\end{array}$ & 4.70 \\
\hline $\begin{array}{c}\text { Simple } \\
\text { extraction }\end{array}$ & 0.20 \\
\hline
\end{tabular}

$\mathrm{APT}=$ all posterior teeth $*=$ article available in German language

\section{REFERENCES}

1. Killey HC, Kay LW. An analysis of 250 cases of oro-antral fistula treated by buccal flap operation. Oral Surg Oral Med Oral Pathol 1967, 24: 726-739.

2. Punwutikorn J, Waikakul A, Pairuchvej V. Clinically significant oroantral communications - A study of incidence and site. Int J Oral Maxillofac Surg 1994; 23:19-21.

3. Von Wowern N. Frequency of oro-antral fistulae after perforation to the maxillary sinus. Scand J Dent Res 1970; 78(5):394-6.

4. Ehrl PA. Oroantral communication. Epicritical study of 175 patients, with special concern to secondary operative closure. Int J Oral Surg 1980; 9:351-8.

5. Rothamel D, Wahl G, d'Hoedt B, Nentwig GH, Schwartz F Becker J. Incidence and predictive factors for perforation of the maxillary antrum in operations to remove upper wisdom teeth: prospective multicentre study. Br J Oral Maxillofac Surg 2007; 45:387-391.

6. Amaratunga NAS. Oroantral fistulae - a study of clinical, radiological and treatment aspects. Br J Oral Maxillofac Surg 1986. 24:433-437.

7. del Rey-Santamaria M, Valmaseda CE, Berini AL, Gay EC. Incidence of oral sinus communications in 389 upper third molar extraction. Med Oral Patol Oral Cir Bucal 2006; 11:334-8..

8. Hasegawa T, Tachibana A, Takeda D et al. Risk factors associated with oroantral perforation during surgical removal of maxillary third molar teeth. Oral Maxillofac Surg 2016; 20: 369-375.

9. Dym H, Wolf JC. Oroantral communication. Oral and Maxillofac Surg Clinics N Am 2012;24: 239-247

10. Demetoglu U, Ocak H, Bilge S. Closure of Oroantral Communication with Plasma-Rich Fibrin Membrane. J Craniofac Surg2018. 29: 367-370.

11. Al-Juboori MJ, Al-Attas MA, Magno Filho LC. Treatment of chronic oroantral fistula with platelet-rich fibrin clot and collagen membrane: a case report. Clin Cosmet Investig Dent2018; 10:245-249.

12. Bilginaylar K. The Use of Platelet-Rich Fibrin for Immediate Closure of Acute Oroantral Communications: An Alternative Approach. J Oral Maxillofac Surg2018; 76:278-286.

13. Światkowski W, Rahnama M, Zebrowska E, Baszak J .Investigation on oroantral communication rate. Dental and Medical Problems 2014; 51(2):173-177

14. Arrigoni J,Lambrecht JT. Komplikationen bei und nach operative weisheitzahnentfernung (complication during and after third molar extraction). Schweiz Monatsschrzahnmed2004; 114:171-86.

15. Hirata Y, Kino K, Nagaoka S, Miyamoto R, Yoshimasu H, Amagasa S. A clinical investigation oro-maxillary sinus perforation due to tooth extraction. Kokubyo Gakkai Zasshi 2001; 68: 249-53.

16. Bodner L, Gatot A, Bar-Ziv J. Technical note: oroantral fistula: improved imaging with a dental computed tomography software program. Br J Radiol1995; 68:124950 .

17. Guven O. A clinical study on oroantral fistulae. J Craniomaxillofac Surg1998; 26:267-71.

18. Hernando J, Gallego L, Junquera L, Villarreal P. Oroantral communications. A retrospective analysis. Med Oral Pathol Cir Bucal 2010; 15:499-503.

19. Mohammed JA. Oroantral communication - A Clinical and radiographic retrospective study of 39 Iraqi patient. MDJ 2013; 10:88-94.

20. Abuabara A, Cortez AL,Passeri LA, de Moraes M ,Moreire RW. Evaluation of different treatment for oroantral/ oronasal communication: experience of 112 cases. Int $j$ oral and Maxillofac surg 2006;35:155-8

21. Beckedorf H, Sonnabend E. The incidence of maxillary sinus perforation in teeth extraction. Zahnartztl Rudsch 1954;66:566-9. 
22. Hanihara T. Comparison of craniofacial features of major human groups. Am J Phys Anthropol1996; 99: 389-412.

23. Marszal K.The significance of selected anatomical details of the maxillary sinus in dental treatment planning - a literature review. Dental Forum2013;41:69-74
24. Fraco- carro B, Barona -Dorado C, Martinez- Gonzalez MJ, Rubio-AlonsoLJ,Martinez-Gonzalez JM. Metaanalytic study on the frequency and treatment of oral antral communication. Med Oral Pathol Cir Bucal 2011; 16:6827. 